\title{
Oral field cancerization: an update on current concepts
}

\author{
Meenakshi Mohan, Nithya Jagannathan \\ Department of Oral Pathology, Saveetha Dental College, Saveetha University, Chennai, India
}

\begin{abstract}
There always exists a field with genetically altered cells with a high risk of developing premalignant and malignant lesions. It may often happen that an individual stem cell is genetically altered and can cause the formation of a clone or a patch which is likely to turn into a tumor. This explains the higher recurrence rates following tumor resections. It is essential to identify and to treat this field in order to have greater chances to prevent cancer and achieve a better outcome. This article reports concepts, theories and markers for the assessment of field cancerization.
\end{abstract}

\section{Introduction}

The oral cavity is one of the predominant and prevalent sites of development of potential malignancies, since it comes into direct contact with many carcinogens. The squamous cell carcinoma is one of the most common malignancies developed in the oral cavity with an average survival rate of about 5 years. ${ }^{1}$ Despite monitoring the original tumor site following an advanced surgical and non-surgical therapy, the overall mortality rate remains unchanged probably due to the recurrence of the tumor either locally or at a remote site. ${ }^{2}$ The devel-

Correspondence: Nithya Jagannathan, Department of Oral Pathology, Saveetha Dental College, Saveetha University, No 162, Poonamalle High Road, Vellapanchavadi, 600077 Chennai, India.

Tel.: +91.9884754910. E-mail: dr.nithya@ymail.com

Key words: cancerization, clone, field, patch, metastasis, tumor.

Acknowledgements: the authors thank the Department of Oral Pathology, Saveetha Universityk, for their support and guidance in the preparation of the article.

Contributions: MM, collection of references and compilation of data; NJ, formatting, preparation and reviewing the article.

Conflict of interests: the authors report no potential conflict of interests.

Received for publication: 17 December 2013.

Revision received: 4 April 2014.

Accepted for publication: 27 April 2014.

This work is licensed under a Creative Commons Attribution NonCommercial 3.0 License (CC BY-NC 3.0).

(C) Copyright M. Mohan and N. Jagannathan, 2014

Licensee PAGEPress, Italy

Oncology Reviews 2014; 8:244

doi:10.4081/oncol.2014.244 opment of recurrences and second primary tumors, even when surgical margins are histopathologically tumor-free corroborates the concept of field cancerization. ${ }^{3}$

Field cancerization also called field defect or field effect is a wellknown process of transformation of an existing precancerous lesion into a malignancy. ${ }^{4}$ Oral field cancerization implies that oral cancer does not arise as an isolated cellular phenomenon, but rather as an anaplastic tendency involving many cells at once that results into a multifocal development process of cancer at various rates within the entire field in response to a carcinogen, such as in particular tobacco. ${ }^{5}$ This definition is often used to describe the development of abnormal tissues around a tumorigenic area, resulting into an oral multifocal cancer in individual sites, which later coalesce and create atypical areas, even after complete surgical removal. This may explain the cause for second primary tumors and recurrences. ${ }^{6}$

Prolonged exposure to carcinogens alters the state of the epithelium, making it susceptible to developing a multifocal carcinoma, which can also derive from independent mutations in the absence of any genetic influence. Multifocal areas of precancerous alterations may trigger this process without involving in particular an individual cell which becomes malignant. ${ }^{7}$ This process may explain the high recurrence rate of carcinomas even after the patient undergoes surgery and radiation therapy. Tumor recurrence is most often due to changes in the preconditioned epithelium, now more prone to cancer, which is located next to the suture line or has healed over the site of a tumor eliminated by radiation therapy. ${ }^{7}$

\section{Criteria used to diagnose multiple carcinomas}

Warren and Gates initially formulated a set of criteria to diagnose multiple primary carcinomas which were modified later by Hong et $a l .{ }^{8,9}$ The criteria to be met are as follows: i) the neoplasm must be distinct and anatomically separate. A multi-centric primary neoplasm is diagnosed when a dysplastic mucosa is present next to it; ii) a potential second primary carcinoma which represents a metastasis or a local relapse should be excluded. It has to occur 3 years after the initial diagnosis or it should be separate from the first tumor by at least $2 \mathrm{~cm}$ from the normal epithelium.

Numerous factors determine the progression of a field into a new tumor and must therefore be accurately reviewed and followed up. A pre-malignant field often requires a much longer period of approximately 67-96 months to progress into an invasive carcinoma. ${ }^{10,11}$

\section{History of field cancerization}

The concept and the definition of field cancerization was first introduced by Slaughter et al. in 1953, when he analyzed the tissues adjacent to 
squamous cell carcinoma. ${ }^{12}$ The concept was first examined in the aerodigestive tract, where multiple primary tumors and local recurrent tumors originate from the anaplastic tendency of multiple cells. The term lateral cancerization was coined later to suggest the lateral spread of tumors, which occurs due to a progressive transformation of the tissue adjacent to the tumor rather than the expansion of pre-existing cancer cells into the adjacent tissue..$^{13}$ On the basis of a broad analysis of 783 carcinoma patients, Slaughter et al. observed that the entire epithelium adjacent to the tumor exhibited more than one independent area of malignancy Later, the expression of field cancerization was adopted, as these findings suggested that the exposure to carcinogen-induced mucosal changes makes the adjacent area susceptible to multiple malignant foci. The concept of field cancerization was extended to other organs, including oropharynx, esophagus, lungs, stomach, colon, cervix, anus, skin and bladder. ${ }^{14}$

The oral cavity was proven to be most susceptible to this process, as it is exposed to a wide range of environmental carcinogens which affect the entire mucosa and result into the simultaneous occurrence of premalignant states. This led to various molecular analyses to investigate the genetic mutations and clonality to validate this carcinogenesis model. ${ }^{14}$ In particular these findings were reported in 1950's when the Watson and Crick model was first described. Later numerous molecular techniques provided unequivocal evidence supporting the concepts proposed by Slaughter et al. ${ }^{6}$

\section{Concept of field cancerization}

Field cancerization involves the formation of multiple patches of premalignant disease with a higher-than-expected rate of multiple local second primary tumors. ${ }^{15}$ In the oral cavity, tobacco and alcohol act in synergy as primary carcinogens in the development of squamous cell carcinomas. The environmental carcinogens reach simultaneously a large area and can damage a large proportion of cells contributing to premalignant states within the entire surface exposed. ${ }^{14}$

The process of carcinogenesis initiates from multiple genetic and epigenetic alterations in the mucosa which can lead to the clonal expansion of premalignant daughter cells in a particular field. ${ }^{16}$ The genetically altered stem cells form a clonal unit comprising daughter cells from which the patch expands into the adjacent areas in subsequent steps following further modifications. ${ }^{14}$ This triggers sequential cellular transformations that ultimately lead to the replacement of the normal epithelium by a proliferating field (Figure 1). However, there is a population of cells with early genetic changes, which does not demonstrate any histological alterations, thus explaining the concept of field cancerization. ${ }^{12}$

\section{Patches: field precursor lesions}

In the epithelium, there is a cluster of cells with cancer-related genetic alterations which can be demonstrated by TP53 immunostatining. ${ }^{17}$ These clusters were named patches by Garcia et al. and were considered equivalent to a clone or a clonal unit. ${ }^{18}$ They were defined as a small group of cells which share a contiguous common genotype at the time of observation. ${ }^{18}$ These patches are usually positive for TP53 in the normal mucosa of patients with head and neck squamous cell carcinoma and are frequent in multiple primary head and neck tumors. ${ }^{19,20}$ These units with transit stem cells and amplifying cells which undergo differentiation make up the squamous epithelium. When a stem cell develops a genetic alteration, the cells derived from it continue to carry the same clonal patch resulting in the formation of a cluster containing TP53 immunopositive cells. ${ }^{18}$

\section{Theories of field cancerization}

Three theories have been postulated to explain the occurrence of carcinomas in specific sites (Figure 2). One theory states that multiple squamous cell lesions occur independently of each other. This is due to the exposure of the oral cavity to carcinogens in at the same time leading to multiple genetic abnormalities in the entire area. ${ }^{12}$ An alternative theory states that multiple lesions arise due to the migration of dysplastic and altered cells with two different patterns, ${ }^{21,22}$ as follows: i) migration of malignant cells through the saliva (micro metastasis); ii) intra-epithelial migration of the progeny of initially transformed malignant cells. This is different from the metastasis, since malignant cells are usually encountered by the lymph nodes and blood where they first develop.

There are two methods of investigation to assess these theories. ${ }^{23}$ The first method considers the alterations in the tumor adjacent mucosa in the histologically normal tumor adjacent mucosa in smokers and drinkers of alcoholic beverages and in the normal tumor adjacent mucosa of non-smokers and non-drinkers. ${ }^{24}$ The tumor adjacent mucosa in head and neck squamous cell carcinoma smokers and nonsmokers shows migrating tumor cells and therefore similar alterations. However these cells are usually absent in healthy smokers. Furthermore, the presence of migrating cells in tumor-adjacent mucosa (TAM) in advanced tumors are usually identical to the alterations in

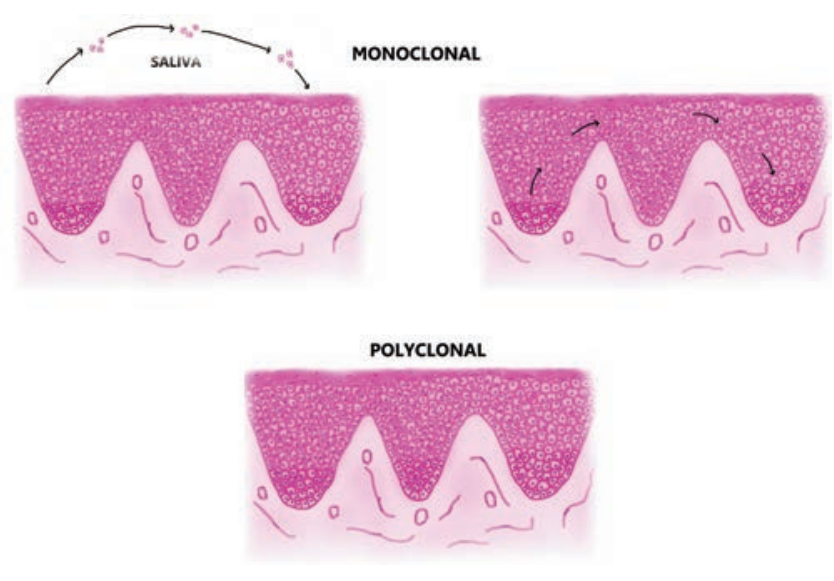

Figure 1. Field cancerization model: evolution of a normal epithelium to a patch, a field and a fully invasive carcinomatous lesion.

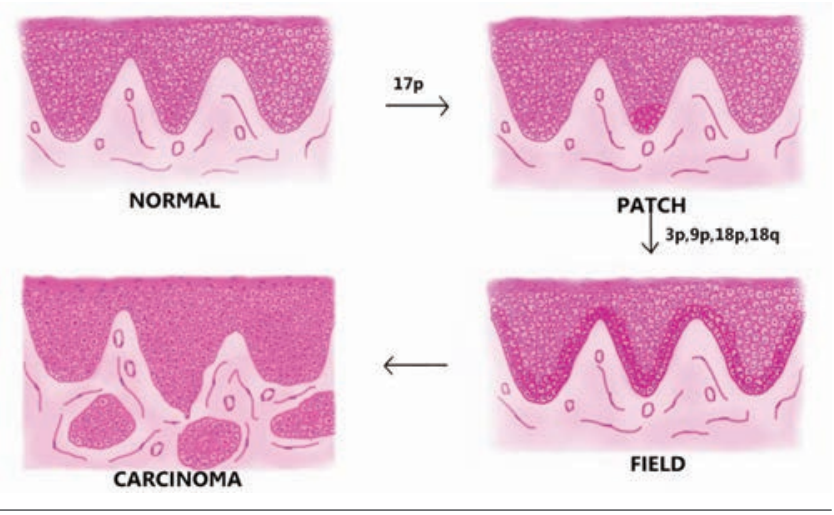

Figure 2. Theories of field cancerization. 
the primary tumor, whereas the presence of migrating progenitor cells in TAMs suggests that at least a few early tumorigenic alterations are identical in the tumor adjacent mucosa and in the invasive tumor. In a few smoking head and neck squamous cell carcinoma patients, there are no migrating cells, thus suggesting that they are smoking-induced independent events. Similarly there are also alterations in the tumor adjacent mucosa in head and neck carcinoma patients which are present in the normal mucosa of healthy smokers..$^{24,25}$

The second method of investigation is based on the clonality of the multiple malignant and premalignant lesions by determining genetic alterations in head and neck squamous cell carcinoma patients. ${ }^{22,26}$ Two separate lesions are said to develop from a single clone when they share common genetic alterations. This clonal relationship between several premalignant and malignant lesions suggests that the tumor cells or the progenitor cells drift and result in cancerization. ${ }^{27}$ However in the absence of a clonal relationship between multiple lesions, it is more likely that they derive from an independent event. ${ }^{28}$

\section{Field cancerization model}

The process of carcinogenesis begins with a stem cell which develops one or more genetic and epigenetic alterations. Subsequently a clone of genetically altered cells forms a patch or a cluster. As a result of further genetic alterations, the stem cell escapes the normal growth control pattern and gains advantage by developing into an expanding clone. Later the lesions progress and become a field which displaces laterally the normal epithelium. The field, having a genetically altered clonal unit, has an enhanced proliferative activity which is the driving force of the entire process. ${ }^{26}$.As the lesions grow in size, additional genetic hits arise in the region resulting in various sub-clones within the field. The clones diverge at different times creating a relatively large number of altered stem cells due to clonal divergence and selection. However they share the same clonal origin. Eventually this process ends up in the formation of an invasive cancer. The probability of developing cancer from a genetically altered stem cell depends on the nature of the affected stem cell itself and of additional hits. The carcinogenesis model we propose is therefore based on a monoclonal origin and includes three main steps: ${ }^{29}$

- First phase (patch formation): conversion of a single stem cell (patch) into a group of cells (clone) which carry the genetic alterations without a proper growth control pattern.

- Second phase (clonal expansion): additional genetic alterations develop and the patch proliferates taking advantage of its enhanced growth potential and forms a field which displaces the normal epithelium.

- Third phase (transition to tumor): the clone or field eventually turns into an overt carcinoma with invasive growth and metastasis.

\section{Molecular concepts of field cancerization}

The expression of various markers in the epithelium and connective tissue components can help determine the field cancerization (Table 1). 1,17,24,29-67 Molecular findings indicate the presence of cytokeratin 7 , $8,13,16$ and 19 at abnormal sites and abnormal levels within the epithelium. ${ }^{56,68}$ Also well-defined foci of cyclin D1 expression are present in the normal mucosa adjacent to the carcinomatous areas. ${ }^{29}$ Several studies have shown a rise in the levels of epidermal growth fac- tor receptor in the tumor-associated normal mucosa. ${ }^{25,40,41,44,69-72} \mathrm{~A}$ fivefold increase in the levels of messenger ribonucleic acid (mRNA) of transforming growth factor was observed. ${ }^{44}$ Increased levels of proliferating epithelial cells were demonstrated using the proliferating cell nuclear antigen and the argyrophilic nucleolar organizer region (AgNOR). ${ }^{58,73}$ A rise in Ki-67 expression was also observed and suggests an increased number of proliferating cells. ${ }^{59}$

Also marked variations in the expression of enzymes were detected in the epithelium. The expression of isoenzyme glutathione S-transferase was found to be significantly higher in the supra-basal and superficial layers of the normal oral mucosa in head and neck carcinoma patients. In the literature also an increase in the detoxification enzymes was reported, which is intriguing, since they protect against carcinogenic attacks. ${ }^{62}$

Vascular markers like VwF and CD31 have also proved to be particularly high in the normal mucosa adjacent to carcinomatous areas due to the upregulation of angiogenic stimulators like the vascular endothelial growth factor or in association with the downregulation of angiogenic inhibitors. ${ }^{45}$ The most promising marker of field cancerization is p53 which shows a strong positive correlation with the progression of the tumor from a benign to a malignant state..$^{30}$

\section{Concepts of field cancerization based on clonality models}

Oral field cancerization occurs by either cell migration or development from independent cells. If multiple tumors occur from the migration of cells from their primary source, the genetic alterations of the primary cell are carried over to all the progenitor cells. However in case of independent cells, the process is different. The assessment of a clonal marker based on the early identification of genetic events is important to investigate the development of the primary lesion and its progression through the expansion of cells. ${ }^{25}$ The method used initially was the $\mathrm{X}$ chromosome inactivation which occurred when large patches of cells were derived from a common ancestor especially during embryonic development. ${ }^{74}$ Later, karyotyping was used in the metaphase stage to compare their appearance and detect ploidy and chromosomal breaks. ${ }^{75}$ Further 6 microsatellite assays with markers like 3p, 8p, 9p, 13q, and Rb were performed. The detection of mitochondrial DNA mutations was also performed. Currently p53 mutations are used as clonal markers for multiple primary tumors, as their expression has been observed in the normal tissue far from the tumor sites. ${ }^{76}$

\section{Chromosomal aberrations in the field}

A trend towards anuesomies of chromosomes 2, 6 and $\mathrm{Y}$ were observed in the normal mucosa of smokers. Polysomies of chromosomes 7 and 17 has also been reported in distant tumor sites along with a loss in chromosome Y. Allelic loss of chromosome 13q14 has also been detected using the jicrosatellite analysis. ${ }^{77}$ This suggests that allelic loss can precede the histological changes in head and neck cancer. Metastatic tumors demonstrate an overpresentation of chromosomes $5 p, 6 p$ and $7 p$. Nodal involvements are characterized by a deletion on chromosome 7q, 10q, 11p, 11q, 15q and 20p and an over representation of chromosomes $19 q$ and $20 q$. This molecular analysis predicts the metastatic tendency in head and neck squamous cell carcinoma patients. ${ }^{78}$ 


\section{Clinical implications and consequences}

It is often noticed that a tumor arises from a site where a surgical excision of the tumor was performed in the same anatomic area. This kind of recurrence from a site where surgery was performed to remove completely a tumor explains the concept of field cancerization. ${ }^{79,80}$ The presence of genetically altered cells in a particular field acts as a risk factor for cancerization and has important consequences. ${ }^{26}$ The presence of pre-neoplastic cells in larger numbers in a proliferating field is likely to be associated with a high risk of malignant transformation. ${ }^{16}$ The probability of developing a second primary tumor in a patient with a history of previous squamous cell carcinoma is around $20 \% .{ }^{81}$

The detection of this field which is prone to the development of cancer is based on the identification of molecular signatures in a genetically transformed, yet histologically normal field called peri-tumoral cancer field. This relies on tumor markers, which are specific for the tumor. Hence the identification of these reliable tumor biomarkers will help monitor the progression of the tumor, thus preventing the transformation of pre-malignant lesions into an invasive cancer..$^{82}$ To date,

Table 1. Markers in the determination of field cancerization.

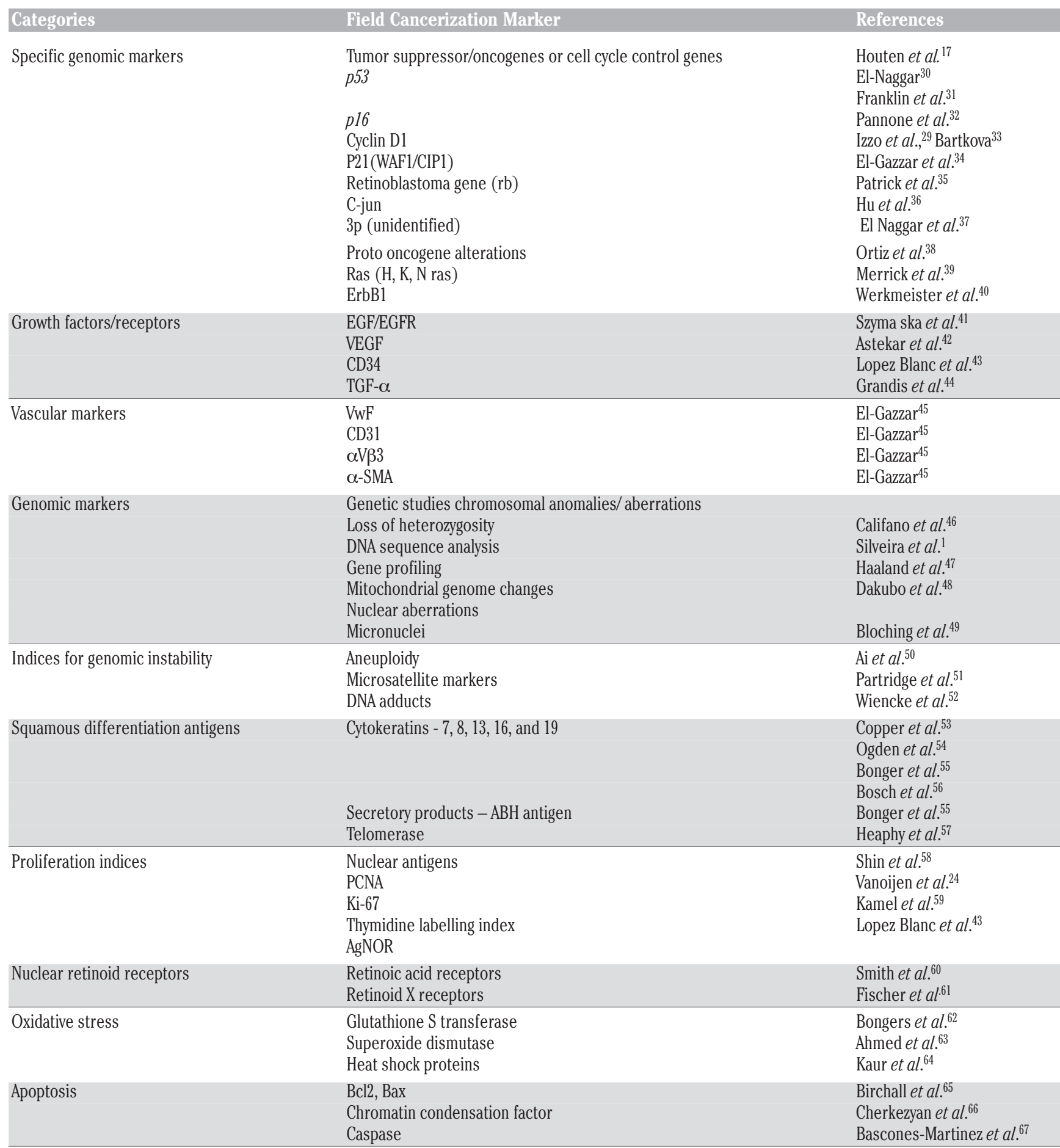


several tumor biomarkers have been reported in various types of cancer, including cancer in the head and neck region, ${ }^{6}$ lungs,${ }^{31}$ colon, rectum,,${ }^{83,84}$ breast, ${ }^{85}$ stomach, ${ }^{86}$ prostrate ${ }^{87,88}$ and bladder. ${ }^{89}$ Several markers have been used to analyze the molecular aspects of the tumor-adjacent normal tissue and surgical margins to determine the presence of field lesions. The markers commonly used are loss of heterozygosity, microsatellite alterations, chromosomal instability, mutations in the p53 gene, which are generally detected by polymerase chain reaction, immunohistochemistry and in situ hybridization. ${ }^{90}$

\section{Understanding the terminology}

The definition of second primary tumor is exclusive intended for second tumors which arise independently from the first tumor. However, when the history shows the occurrence of a second tumor arising from the same field, it is always preferable to use the definition of second field tumor (SFT). It is important to mark this difference, since clinical consequences can vary with differing etiologies. It is also to be noted that third and fourth field tumors arise from secondary field tumors. Hence a routine follow-up is mandatory in cases of SFT. The definition of local recurrence applies to lesions arising from the remaining tumor cells and local residues of the field which develop into cancer. Hence, a local recurrence is also a form of SFT. ${ }^{91}$

\section{Conclusions}

The definition of field cancerization refers to a group of genetically altered clones of cells in multifocal patches, which are prone to the development of synchronous and metachronous tumors. The field cancerization theory also emphasizes the high probability of recurrences in patients with head and neck squamous cell carcinoma. Therefore a frequent oral examination with histological studies and molecular testing are mandatory for patients after surgery, especially for those at high risk of developing malignancies. Though numerous markers have been identified to help determine the field effect, the entire process is still controversial, therefore further investigations are still in progress to gain a better understanding of carcinogenesis and to use the biomarkers foreseen in this concept for cancer prevention purposes.

\section{References}

1. Silveira NJ, Varuzza L, Machado-Lima A, et al. Searching for molecular markers in head and neck squamous cell carcinomas (HNSCC) by statistical and bioinformatic analysis of larynxderived SAGE libraries. BMC Med Genomics 2008;1:56.

2. Marcus B, Arenberg D, Lee J, Kleer C, et al. Prognostic factors in oral cavity and oropharyngeal squamous cell carcinoma. Cancer 2004;101:2779-87.

3. Leemans CR, Tiwari R, Nauta JJ, et al. Recurrence at the primary site in head and neck cancer and the significance of neck lymph node metastases as a prognostic factor. Cancer 1994;73:187-90.

4. Braakhuis BJ, Brakenhoff RH, Leemans CR. Second field tumors: a new opportunity for cancer prevention. Oncologist 2005;10:493-500.

5. Slaughter DP The multiplicity of origin of malignant tumors: collective review. Int Abstr Surg 1944;79:89-98.

6. Braakhuis BJ, Tabor M, Kummer JA, et al. A genetic explanation of Slaughter's concept of field cancerization: Evidence and clinical implications. Cancer Res 2003;63:1727-30.

7. Ha P, Califano J. The molecular biology of mucosal field cancerization of the head and neck. Crit Rev Oral Biol Med 2003;14:363-9.

8. Hong WK, Lippman SM, Itri LM, et al. Prevention of second primary tumors with isotretinoin in squamous-cell carcinoma of the head and neck. N Engl J Med 1990;323:795-801.

9. Warren $\mathrm{S}$, Gates 0 . Multiple primary malignant tumors. A survey of the literature and a statistical study. Am J Cancer 1932;16:1358-414.

10. Scholes AG, Woolgar JA, Boyle MA, et al. Synchronous oral carcinomas: independent or common clonal origin? Cancer Res 1998;58:2003-6.

11. Mao L, Lee JS, Fan YH, et al. Frequent microsatellite alterations at chromosomes 9p21 and 3p14 in oral premalignant lesions and their value in cancer risk assessment. Nat Med 1996;26:682-5.

12. Slaughter M, Danely P, Harry W, et al. Field cancerization in oral stratified squamous epithelium clinical implications of multicentric origin. Cancer 1953;6:963-8.

13. Slaughter DP. Multicentric origin of intraoral carcinoma. Surgery 1946;20:133-46.

14. Kaufmann R. The concept of field cancerization. Melanoma Res 2010;20:e13-4.

15. Patrick K, Joseph HA, Califano A. The molecular biology of mucosal field cancerization of the head and neck. Crit rev Oral Biol Med 2003;14:363-9.

16. Manjunath SM, Sabharwal R, Kumar M, et al. Oral field cancerization: an update. Univ Res J Dent 2014;4:10-5.

17. Van Houten VM, Tabor MP, Van-Den B, et al. Mutated P53 as molecular marker for the diagnosis of head and neck cancer. J Pathol 2002;198:476-86.

18. Garcia SB, Park HS, Novelli M, Wright NA. Field cancerization, clonality, and epithelial stem cells: the spread of mutated clones in epithelial sheets. J Pathol 1999;187:61-81.

19. Waridel F, Estreicher A, Bron L, et al. Field cancerisation and polyclonal p53 mutation in the upper aerodigestive tract. Oncogene 1997;14:163-9.

20. Jonason AS, Kunala S, Price GJ, et al. Frequent clones of p53mutated keratinocytes in normal human skin. Proc Natl Acad Sci U S A 1996;93:14025-9.

21. Corio R, Lee D, Greenberg B, Koch W, Sidransky D. Genetic Progression model for head and neck cancer: implication for field cancerization. Cancer Res 1996;56:2488-92.

22. Bedi GC, Westra WH, Gabrielson E, et al. Multiple head and neck tumors: evidence for a common clonal origin. Cancer Res 1996;56:2484-7.

23. Van-Diest PJ, Van Der Wall E, Baak JP. Prognostic value of proliferation in invasive breast cancer: A review. J Clin Pathol 2004;57:675-81.

24. Van Oijen MG, Gilsing MM, Rijksen G, et al. Increased number of proliferating cells in oral epithelium from smokers and ex-smokers. Oral Oncol 1998;16:3158-68.

25. Monique G, Oijen V, Slootweg PJ. Oral field cancerization: carcinogen-induced independent events or micrometastic deposits? Cancer Epidemiol Biomarker Prev 2000;9:249-56.

26. Tabor MP, Brakenhoff RH, Van HV, et al. Persistence of genetically altered fields in head and neck cancer patients: biological and clinical implications. Clin Cancer Res 2001;7:1523-32.

27. Partridge M, Pateromichelakis S, Phillips E, et al. Profiling clonality and progression in multiple premalignant and malignant oral lesions identifies a subgroup of cases with a distinct presentation of squamous cell carcinoma. Clin Cancer Res 2001;7:1860-6.

28. Van0ijen MJ, PJ Slootweg. Oral field cancerization: carcinoma induced independent events or micrometastatic deposits. Cancer Epidemiol Biomarker Prev 2000;9:249-56.

29. Izzo JG, Papadimitrakopoulou VA, Li XQ, et al Dysregulated cyclin D1 expression early in head and neck tumorigenesis: in vivo evi- 
dence for an association with subsequent gene amplification. Oncogene 1998;17:2313-22.

30. El-Naggar AK, Lai S, Luna MA, et al. Sequential p53 mutation analysis of the preinvasive and invasive head and squamous carcinoma. Int J Cancer 1995;64:196-20.

31. Franklin WA, Gazdar AF, Haney J, et al. Widely dispersed p53 mutation in respiratory epithelium. A novel mechanism for field carcinogenesis. J Clin Invest 1997;100:2133-7.

32. Pannone G, Rodolico V, Santoro A, et al. Evaluation of combined triple method to detecet causative HPV in oral and oropharyngeal squamous cell carcinomas: p16 immunohistochemistry, consensus PCR HPV-DNA, and in situ hybridization. Infect Agent Cancer 2012;7:4

33. Bartkova J, Lukas J, Müller H, et al. Abnormal patterns of D-type cyclin expression and G1 regulation in human head and neck cancer. Cancer Res 1995;55:949-56.

34. El-Gazzar RF, Nofal RA. Over expression of p53 and p21 in normal oral mucosa adjacent to resected squamous cell carcinomas Egypt Dent Ass 2005;51:835.

35. Patridge M, Emilion G, Pateromichelakis S, et al. Prognostic significance of allelic imbalance at key chromosomal loci in oral cancer. Br J Cancer 1999;79:1821-7.

36. Hu B, Castillo E, Harewood L, et al. Multifocal epithelial tumors and field cancerization from loss of mesenchymal CSL signaling. Cell 2012;149:1207-20.

37. EI-Naggar AK, Lee MS, Wang G, et al. Polymerase chain reactionbased restriction fragment length polymorphism analysis of the short arm of chromosome 3 in primary head and neck squamous carcinoma. Cancer 1993;72:881-6.

38. Ortiz BH, Ailawadi M, Colitti C, et al. Second primary or recurrence? Comparative patterns of p53 and K-ras mutations suggest that serous borderline ovarian tumors and subsequent serous carcinomas are unrelated tumors. Cancer Res 2001;61:7264-7.

39. Merrick DT, Kittelson J, Winterhalder R, et al. Analysis of cErbB1/epidermal growth factor receptor and c-ErbB2/HER-2 expression in bronchial dysplasia: evaluation of potential targets for chemoprevention of lung cancer. Clin Cancer Res 2006;12:2281-8.

40. Werkmeister R, Brandt B, Joos U. The erbB oncogenes as prognostic markers on oral squamous cell carcinomas. Am J Surg 1996;172:681-3.

41. Szymańska K, Levi JE, Menezes A, et al. TP53 and EGFR mutations in combination with lifestyle risk factors in tumours of the upper aerodigestive tract from South America. Carcinogenesis 2010;31:1054-9.

42. Astekar M, Joshi A, Ramesh G, Metgud R. Expression of vascular endothelial growth factor and microvessel density in oral tumorigenesis. J Oral Maxillofac Pathol 2012;16:22-6.

43. López-Blanc SA, Collet AM, Gandolfo MS, et al. Nucleolar organizer regions (AgNOR) and subepithelial vascularization as field cancerization markers in oral mucosa biopsies of alcoholic and smoking patients. Oral Surg Oral Med Oral Pathol Oral Radiol Endod 2009;108:747-53.

44. Grandis JR, Tweardy DJ. Elevated levels of transforming growth factor alpha and epidermal growth factor receptor messenger RNA are early markers of carcinogenesis in head and neck cancer. Cancer Res 1993;53:3579-84.

45. El-Gazzar R, Macluskey M, Ogden GR. Evidence for a field change effect based on angiogenesis in the oral mucosa? A brief report. Oral Oncol 2005;41:25-30.

46. Califano J, Van Der Riet P, Westra W, et al. Genetic progression model for head and neck cancer: implications for field cancerization. Cancer Res 1996;56:2488-92.

47. Haaland CM, Heaphy CM, Butler KS, et al. Differential gene expression in tumor adjacent histologically normal prostatic tissue indi- cates field cancerization. Int J Oncol 2009;35:537-46.

48. Dakubo GD. Early cancer detection and monitoring using changes in the mitochondrial genome as biosensors. Chapter 12. In: Dakubo GD, ed. Mitochondrial Genetics and Cancer. Heidelberg, Dordrecht, London, New York: Springer; 2010. pp 275-92.

49. Bloching M, Hoffman A, Berghaus A. Micronuclei as biological markers for the detection of local cancer transformation in the upper aerodigestive tract. HNO 2000;48:444-50.

50. Ai H, Barrera J, Pan Z, et al. Identification of individuals at high risk for head and neck carcinogenesis using chromosome aneuploidy detected by fluorescence in situ hybridization. Mutat Res 1999;439:223-32.

51. Partridge M, Pateromichelakis S, Phillips E, et al. A case control study confirms that microsatellite assay can identify patients at risk of developing oral squamous cell carcinoma within a field of cancerization. Cancer Res 2000;60:3893-8.

52. Wiencke JK. DNA adduct burden and tobacco carcinogenesis. Oncogene 2002;21:7376-91.

53. Copper MP, Braakhuis BJ, De-Vries N, et al. A panel of biomarkers of carcinogenesis of the upper aerodigestive tract as a potential immediate endpoints in chemoprevention trials. Cancer 1993;71: 825-30.

54. Ogden GR, Lane EB, Hopwood DV, Chisholm DM. Evidence of field change in oral cancer based on cytokeratin expression. Br J Oral Maxillofac Surg 1993;67:1324-30.

55. Bongers V, Snow GB, De-Vries N, Braakhuis BJ. Potential early markers of carcinogenesis in the mucosa of the head and neck using exfoliative cytology. J Pathol 1996;178:284-9.

56. Bosch FX, Ouhayoun JP, Bader BL, et al Extensive changes in cytokeratin expression patterns in pathologically affected human gingiva. Virchows Arch B Cell Pathol 1989;58:59-77.

57. Heaphy CM, Bisoffi M, Fordyce CA, et al. Telomere DNA content and allelic imbalance demonstrate field cancerization inhistologically normal tissue adjacent to breast tumors. Int $\mathrm{J}$ Cancer 2006;119:108-16.

58. Shin DM, Ro JY, Hong WK, Hittelman WN. Sequential increase in proliferating cell nuclear antigen expression in head and neck tumorigenesis: a potential biomarker. J Natl Cancer Inst 1993;85:971-8.

59. Kamel OW, Franklin WA, Ringus JC, Meyer JS. Thymidine labelling index and ki 67 growth fraction in lesions of the breast. Am J Pathol 1989;134:107-13.

60. Smith W, Saba N. Retinoids as chemoprevention for headand neck cancer: where do we go from here? Crit Rev Oncol Hematol 2005;55:143-52.

61. Fisher GJ, Voorhees JJ. Molecular mechanisms of retinoid actions in skin. FASEB J 1996;10:1002-13.

62. Bongers V, Snow GB, De-Vries N, et al. Second primary head and neck squamous cell carcinoma predicted by the glutathione $\mathrm{S}$ transferase expression in healthy tissue in the direct vicinity of the first tumor. Lab Invest 1995;73:503-10.

63. Ahmed AM. Salivary antioxidants superoxide dismutase and glutathione peroxidase in smokers comparing to non-smokers J. Bio Sci Res 2013;4:4-9.

64. Kaur J, Ralhan R. Differential expression of 70-kDa heat shockprotein in human oral tumourigenesis. Int J Cancer1995;63:774-9.

65. Birchall MA, Schock E, Harmon BV, Gobé G. Apoptosis, mitosis, PCNA and bcl-2 in normal, leukoplakia and malignant epithelia of the human oral cavity: prospective, in vivo study. Oral Oncol 1997;33:419-25.

66. Cherkezyan L, Stypula-Cyrus Y, Subramanian H, et al. Nanoscale changes in chromatin organization represent the initial steps of tumorigenesis: a transmission electron microscopy study. BMC Cancer 2014;14:189. 
67. Bascones-Martínez A, Rodríguez-Gutierrez C, Rodríguez-Gómez E, et al. Evaluation of p53, Caspase-3, Bcl-2, and Ki-67 markers in oral squamous cell carcinoma and premalignant epithelium in a sample from Alava Province (Spain). Med Oral Patol Oral Cir Bucal 2013;18:e846-50.

68. Bloching M, Soulsby H, Naumann A, et al Tumor risk assessment by means of immunocytochemical detection of premalignant chages in buccal smears. Oncol Rep 2008;19:1373-9.

69. Eisbruch A, Blick M, Lee JS, et al. Analysis of the epidermal growth factor receptor gene in fresh human head and neck tumors. Cancer Res 1987;47:3603-5.

70. Christensen ME, Engbaek F, Therkildsen MH, et al. A sensitive enzyme-linked immunosorbent assay used for quantitation of epidermal growth factor receptor protein in head and neck carcinomas: evaluation, interpretations and limitations. Br J Cancer 1995;72:1487-93.

71. Shin DM, Ro JY, Hong WK, Hittelman WN. Dysregulation of epidermal growth factor receptor expression in premalignant lesions during head and neck tumorigenesis. Cancer Res 1994;54:3153-9.

72. Bergle W, Bier H, Ganzer U. The expression of epidermal growth factor receptors in the oral mucosa of patients with oral cancer. Arch Otorhinolaryngol 1989;246:121-5.

73. Schwindt AE, Savino TM, Lanfranchi HE, et al. Nuclear organizer regions in lining epithelium adjacent to squamous cell carcinoma of human oral mucosa. Cancer 1994;73:2674-9.

74. Weinberg WC, Howard JC, Iannaconne PM. Histological demonstration of mosaicism in a series of chimeric rats produced between congenic strains. Science 1985;227:524-7.

75. Worsham MJ, Wolman SR, Carey TE, et al. Common clonal origin of synchronous primary head and neck squamous cell carcinomas: analysis by tumor karyotypes and fluorescence in situ hybridization. Human Pathol 1995;26:251-61.

76. Shin DM, Kim J, Ro JY, et al Activation of p53 expression in premalignant lesions during head and neck tumorigenesis. Cancer Res 1994;54:321-6.

77. Lee N, Ye Y, Li X, et al. Allelic loss on chromosome 13 can precede histological changes in head and neck cancer. Int $\mathrm{J}$ Oncol 1994;5:205-10.

78. Welkoborsky HJ, Bernauer HS, Riazimand HS, et al. Patterns of chromosomal aberrations in metastasizing and nonmetastasizing squamous cell carcinomas of the oropharynx and hypopharynx. Ann Otol Rhinol Laryngol 2000;109:401-10.

79. Gandor DW, Meyer J. A simple two-dye basic stain facilitating recognition of mitosis in plastic embedded tissue sections. Stain Technol 1988;63:75-81.

80. Reibel J. Prognosis of oral pre-malignant lesions: significance of clinical, histopathological, and molecular biological characteristics. Crit Rev Oral Biol Med 2003;14:47-62.

81. Dakubo G, Jakupciak J, Birch-Machin M. Clinical implications and utility of field cancerization. Cancer Cell Inter 2007;7:2.

82. Hong WK, Endicott J, Itri LM, et al. 13-cis-retinoic acid in the treatment of oral leukoplakia. N Engl J Med 1986;315:1501-5.

83. Shen L, Kondo Y, Rosner GL, et al. MGMT promoter methylation and field defect in sporadic colorectal cancer. J Natl Cancer Inst 2005;97:1330-8.

84. Suzuki H, Watkins DN, Jair KW, et al Epigenetic inactivation of SFRP genes allows constitutive WNT signaling in colorectal cancer. Nat Genet 2004;36:417-22.

85. Yan PS, Venkataramu C, Ibrahim A, et al. Mapping geographic zones of cancer risk with epigenetic biomarkers in normal breast tissue. Clin Cancer Res 2006;12:626-36.

86. Endoh M, Tamura G, Honda T, et al. ASSF2, a potential tumour suppressor, is silenced by $\mathrm{CpG}$ island hypermethylation in gastric cancer. Br J Cancer 2005;93:1395-9.

87. Mehrotra J, Varde S, Wang H, et al. Quantitative, spatial resolution of the epigenetic field effect in prostate cancer. Prostate 2008;68:152-60.

88. Nonn L, Ananthanarayanan V, Gann PH. Evidence for field cancerization of the prostate. Prostate 2009;69:1470-9.

89. Takahashi T, Habuchi T, Kakehi Y, et al. Clonal and chronological genetic analysis of multifocal cancers of the bladder and upper urinary tract. Cancer Res 1998;58:5835-41.

90. Punnya VA, Savitha JK, Sanjay S, et al. Oral field cancerization: current evidence and future perspectives. Oral Maxillofac Surg 2012;16:171-80.

91. Boudewijn JMB, Maarten PT, Alain KJ, et al. A genetic explanation of Slaughter's concept of field cancerization: evidence and clinical implications. Canc Res 2003;63:1727-30. 